\title{
The Impact of the Judo's Mental Imagery Learning on the Imaging Ability among High Institute Students
}

\author{
Nasr Chalghaf ${ }^{2}$, Abdelhakim Cherif $^{2}$, Souhir Sbaa $^{2}$, Fairouz Azaiez $^{1,2}$ \\ 1- Higher institute of Sport and the Physical Education of Sfax (Tunisia) \\ 2- Studies Group of Development and Social Environment (Faculty of Social Sciences and letters of Sfax)
}

\begin{abstract}
Mental imagery involves the athletes' imagery themselves in a specific environment or performing a specific activity. Different uses of imagery in sport include: mental practice of specific performance skills, improving confidence, and positive thinking, problem solving, controlling arousal and anxiety, performance review and analysis, preparation for performance and during imagery, (plessenger., 2009). Our study aims to identify the effect of a learning program of mental imagery method in judo standing on the imaging ability. 48 students male divided into three groups of 16 , (mean age $21.0 \pm 1.85$ ) voluntarily participated in this study. Group 1, has a judo mental imagery learning; group 2 has an observational judo learning and group 3 has an analytical judo learning. The revised movement imagery questionnaire $(M I Q-R)$ developed by Hall \& Martin (1997) was used in our study before and after the training programs in order to evaluate the ability of imagery overall the subjects. The statistical data shows that there is progress in the imaging capacity through the application of the three learning methods warranted by the results of the Student test, which is significant at $P<.001$ in favor of the mental imagery group.
\end{abstract}

Keywords: mental imagery; imaging ability; judo

\section{Introduction}

Recent times, sport have been going further from the physical aspect to the mental or psychological aspect of competing and there is growing realization that peak performance in sport can only be achieved through taking help from those psychological techniques which enhance players' psychological strength. Mental imagery is a kind of psychological technique where senses are involved to create sensory experiences in the mind in the absence of the actual physical activity so as to closely resemble the actual movement. It plays a vital role in producing positive states of mind which in turn help the athlete in delivering optimal level of performance. Mental imagery as a cognitive technique is one of the suitable treatment methods to improve athletic performance (Cumming \& al., 2006; Eddy \& al., 2003).

The concept of imagery is used in many different contexts (Taktek, 2004). Sport imagery can be defined as using all sense to re-create or create a sport experience in the mind with the goal of enhancing sport performance during training and competition (Morris, Spittle \& Watt., 2005; Taylor \& Wilson., 2005; Weinberg \& Gould., 2007). It was explained clearly where your brain recalls and reconstructs pieces of information stored in your memory to build a meaningful image. It is means that most athletes can recall previous experiences in great vividness and detail through imagery because according to Hall, (2001) most imagery research has concerned the effect of the cognitive rehearsal of sport skills on subsequent performance. This can be explained by this phenomenon; a softball player may recall what it feels like hit or contact the pitched ball. Athletes can also create images of event yet to occur by piercing together bits of information already stored in their memories.

\section{Mental Imagery and Performance Enhancement}

Block (1983) identified human imagery, the use of visualization to imagine situations, as one of the most important topics in cognitive science. Two general theories were evolved. Furthermore, fisher, (1986) clarifies that imagery is the language of the brain in a real sense; the brain really cannot tell the difference between an actual physical event and the vivid visualization of the same event. For this reason imagery can be used by the brain to provide repetition, elaboration, intensification and preservation of important athletic sequences and skills.

Henschen (2005) noted that imagery is a synonymous with visualization, but this is inaccurate. Visualization is only one form of imagery. Most athletes are both visual and kinesthetic (feelers) imagers. Strangely enough, the more skilled an athlete becomes normally the more a "feeler" they become. The use of imagery as a mental training technique allows performers to draw on their imagination to perfect their performance. Thus, Smith (1987) identified two kinds of imagery, internal and external. Emphasizing the importance of internal and external imagery in sport performance, mahoney and avener (1997) explained that internal perspective means that athletes see the image from behind their own eyes as if they were inside their 
bodies, as opposed to the external perspective in which they see the image from outside their bodies as with a video camera.

\section{Mental Imagery Rehearsal in Sport Skills Acquisition}

In sport, mental imagery is used primarily to help the athlete get the best out of him / her training and in competition. The developing athlete who makes the fastest progress and those who ultimately become their best make extensive use of mental imagery rehearsal. They use it daily as a means of directing what will happen in training and as a way of pre experiencing their best competition performances. Orlick (1990) explained that mental imagery often starts out simply, as you think through your goals, your moves, and your desired competitive performances. With practice it will develop to the point where, through imagery, you can draw on all of your senses to pre experience the achievement of many of your goals, moves, competitive performance and coping strategies. Coaches attending a mental skills training workshop indicated that they used imagery more than any other mental training technique and felt that imagery was the most useful mental technique that they used with athletes (Patterson., 2007).

Many researchers are extending the knowledge of imagery use to understanding exactly how and why athletes use imagery. Besides engaging in cognitive mental practice to enhance athletic skills, imagery has been used by athletes for other motivational reasons, Palvio, (1985). From a sample of 40 elite gymnasts, 92\% reported using imagery to practice skills and strategies, to recall and control emotions, to improve concentration, and to set goals, (Suinn., 2005). For better reasons, we advance the theories that tried to explain how imagery works. These include the psycho-neuro-muscular theory (Jacobson., 1931), the symbolic learning theory (Sackett., 1934), Lang's (1977, 1979) bio-informational theory and the attention arousal set (Schmidt., 2004).

\section{Mental imagery theories}

\section{The Psycho neuro muscular Theory}

This theory states that as athletes engage in sport movement, their brains are constantly transmitting impulse to the muscles for execution of the movement. Similar impulses occur in the brain and muscles when athletes imagine the movements without actually performing them. Thus, the psycho-neuro-muscular theory asserts that vivid imagined events produce, innervations in our muscles similar to that produced by the actual physical execution of the event. Coaches and athletes should know that mental imagery strengthens their muscle memories by having the muscle respond in the correct sequence without actually executing the movement, (Williams., 2010).

\section{The Symbolic Learning Theory}

In this theory, imagery may function as a coding system to help athletes acquire or understand movement patterns. All movements that we make must first be encoded in our central narrow system; we must have a blue print or code their movement into symbolic components, thus making the movement more familiar and perhaps more automatic. For example, a judoka can use imagery to cue himself on the temporal and spatial components involved in the execution of a technical projection (Smith., 2011).

\section{The Bioinformational Theory}

This theory assumes that a mental image is an organized set of propositions or characteristics stored in the brain's long-term memory; (Wrisberg., 2000). When individuals engage in imagery, they activate stimulus characteristics that describe the content of the image for them and response characteristics that describe what their responses are to the stimuli in that situation. According to bio informational theory, for imagery to facilitate athletic performance, response characteristics must be activated so they can be modified, improved and strengthened. By repeatedly accessing response characteristics for a particular stimulus situation and modifying these responses to represent perfect control and execution of a skill, imagery is predicted to enhance performance, (Burton., 2008).

\section{Mental Imagery and Motor Learning}

Main objective of mental imagery exercises are to ensure that there is an increase in physical performance, to remove the negative issues that may occur during competition and to shorten the recovery period in case of any possible injury (Weinberg \& Gould., 2007; Roberts \& al., 2008). Mental imagery exercises ensure that various psychological states that have negative impacts on athletes are minimized, such as stress, anxiety, concern, motivation disorders, depression etc. (Williams., 2006; Bartholomew \& al., 2010). It also ensures that issues that play an important in performance increase improve in positive direction, such as attention, concentration, goal setting, stress management, stimulus control, self-confidence, motivation and communication skills etc. (Mouratidis \& al., 2008; Sarah \& al., 2011; Smith \& al., 2011). In case the athlete does envisioning exercises in his/her brain during recovery and return period following injury, it accelerates the 
healing process in the positive direction as it supports the administered treatment (Gardner \& al., 2006). It is revealed by scientific researches that envisioning exercises make positive contributions to performance increase (Cumming \& al., 2007; Pesce \& al., 2007; Burton \& al., 2008). Envisioning requires experiencing the imagined situation with all of our sense organs. Events that are envisioned clear enough in the mind form stimuli in our brains that are very close to reality (Williams., 2006). Therefore, athletes may benefit from envisioning exercises in order to strengthen, detail, intensify, remember new or former sports skills, and for purposes, such as strategies, sports tactics and techniques, sports rehabilitation etc. (Cox., 2007).

\section{Methods}

48 male students, who had never done mental imagery exercise previously divided into three groups of 16 , (mean age $21.0 \pm 1.85$ ) voluntarily participated in this study. Group 1 has a learning judo imagery program, group 2 has an observational learning and group 3 has an analytical learning. The experiment lasted 8 weeks with 2 hours of learning per week. The revised movement imagery questionnaire (MIQ-R) developed by Hall and Martin (1997) was used in our study before and after the training programs in order to evaluate the ability of imagery overall the subjects.

A training program was used in judo branche in order to improve the impact of the judo mental imagery program on the imaging capacity among students who never either practiced this martial art or done mental imagery exercise previously. The students of the Imagery group shall envision for half an hour, 2 days per week the video motor training of judo standing technical actions done by a high level judoka. The observational learning group chowed the same program entire session. The analytical learning group had judo learning by a judo teacher. Before every learning session, in order that the imagery is more effective when participants are in a relaxed state, different relaxation strategies were introduced during the guided imagery sessions. These included progressive relaxations, tense-relax method, breathing relaxation and imagery relaxation and lasted for 5-10 minutes.

\section{Results}

The table below shows the values of the effect of the application of the three learning methods in imaging ability.

Table 1: Comparison between the three experimental groups at the imaging ability

\begin{tabular}{|c|c|c|c|c|c|c|c|c|}
\hline Groups & Tests & Mean & E T & difference & $\mathbf{N}$ & DDL & $\begin{array}{c}\mathrm{T} \\
\text { Student }\end{array}$ & Décision \\
\hline \multirow{2}{*}{$\begin{array}{l}\text { Mental } \\
\text { imagery } \\
\text { group }\end{array}$} & $\mathrm{T} 1$ & 40 & 3,12 & \multirow[b]{2}{*}{20,875} & 16 & \multirow[b]{2}{*}{15} & \multirow[b]{2}{*}{24,6765} & \multirow{2}{*}{$\begin{array}{c}\mathbf{S} \text { at } \\
\mathbf{P}<.001 \\
\end{array}$} \\
\hline & $\mathrm{T} 2$ & 60,875 & 2,778 & & 16 & & & \\
\hline \multirow{2}{*}{$\begin{array}{l}\text { Observational } \\
\text { group }\end{array}$} & $\mathrm{T} 1$ & 35,875 & 4,87 & \multirow[b]{2}{*}{9,5} & 16 & \multirow[b]{2}{*}{15} & \multirow[b]{2}{*}{6,7175} & \multirow{2}{*}{$\begin{array}{c}\mathbf{S} \text { at } \\
\mathbf{P}<.001\end{array}$} \\
\hline & $\mathrm{T} 2$ & 45,375 & 4,272 & & 16 & & & \\
\hline \multirow{2}{*}{$\begin{array}{l}\text { Analytical } \\
\text { group }\end{array}$} & T1 & 32,875 & 5,201 & \multirow[b]{2}{*}{7,25} & 16 & \multirow[b]{2}{*}{15} & \multirow[b]{2}{*}{5,2888} & \multirow{2}{*}{$\begin{array}{c}\text { S at } \\
\mathbf{P}<.001\end{array}$} \\
\hline & $\mathrm{T} 2$ & 40,125 & 1,668 & & 16 & & & \\
\hline
\end{tabular}

The statistical data in Table 1 shows that there is progress in the imaging ability through the application of the three learning methods warranted by the results of the Student test, which is significant at $\mathrm{P}<.001$ in favor of the mental group with an average difference: 20,875 for group 1 and 9.50 for group 2 and 7.25 for group 3. These findings are illustrated in the following graph:

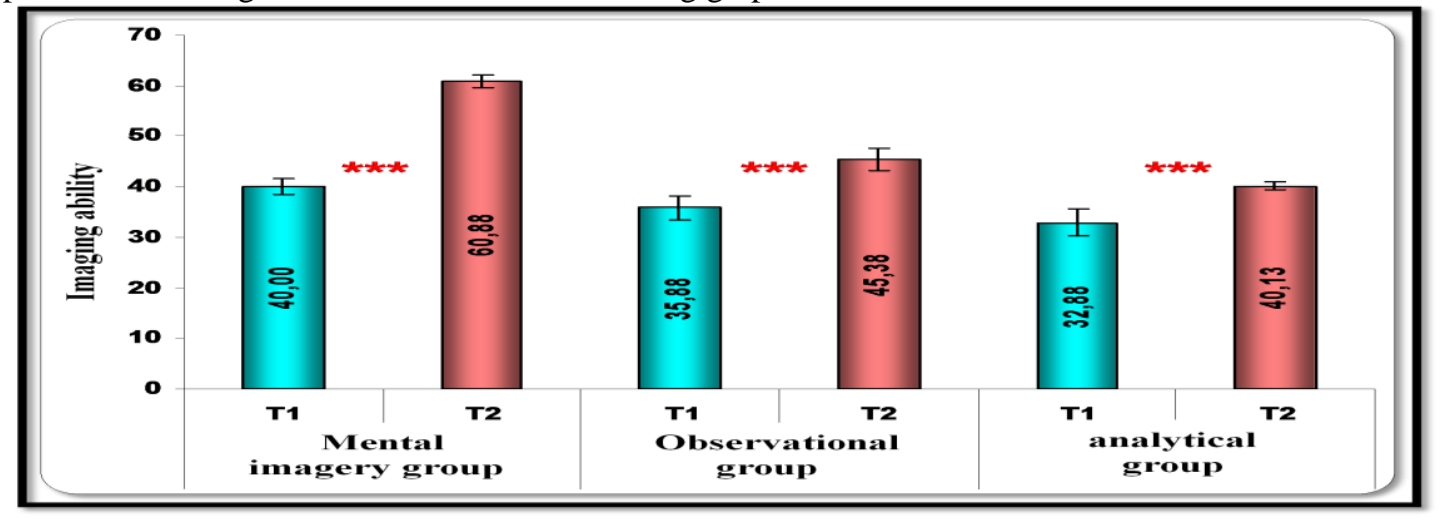

Fig 1: Comparison between the three experimental groups at the imaging capacity 
The illustrated results in ( fig 1) chow us the differences in each group by comparing the results of test 1 (before learning sessions) and ones of test 2 (after learning sessions) which are in favor of the second test that note a remarkable progress of the imaging capacity overall the three groups: (mental imagery group, T1:40,00 ;T2:60,88 / observational group, T1:35,88 ; T2:45,38 / analytical group, T1:32,88; T2:40,13). This progress inter groups is also intra groups in favor of the mental imagery group that fulfilled a progress between (T1 \& T2) about 20,875 , than the second group $(9,50)$ and the last group $(7,25)$.

\section{Discussion}

The data show surprising advances in imaging capacity overall the subjects in favor of the mental imagery group. Fadiga \& Craighero (2004); Jeannrod (1999); Gentili \& al (2006) have raised the role of mental training on the acquisition of 'Internal Model and the capacity for abstraction in the individual. Beyond that, the acquisition of the internal model is even in the absence of movement (Crosbie \& al., 2004). In the same context, Voss \& al (2006) find that motor imagery is equivalent to consciousness the prediction of action.

The analytical group athletes do no attain the same physiological and psychological prowess that mental imagery group athletes do (Stanley., 2004). These imaging capacity level differences among the three groups are because the mental imagery group perceived the critical situation, change strategy quickly and had many options to cope the situation. Based on the several researchers have defined coping as the person's behavioral and cognitive actions to manage the internal and external demands experienced during a stressful situation (Skinner \& al., 2003). So, controlling the situation of the game with this skill can induce the athlete performance. Therefore, the arousal, anxiety and maturity can be enhancing. Furthermore, the reason behind the beneficial results of the mental imagery group compared to the other groups is that its judokas are more concentrated to execute perfectly the judo actions previously stored in their memories (Morris \& al., 2005; Galloway., 2006; Lajcik., 2008). Also these results confirm with the principle of "maximum efficiency" of Kano (2005) that «one's mental and physical energy must be used most effectively in order to achieve a certain goal... One must apply the most effective method or technique for using the mind and body.... You must put your mental and physical energy to work in the most effective manner".

\section{Conclusion}

One of the most significant characteristics of the human brain is that it cannot tell dreams from reality (Cox., 2007). This case provides an advantage in terms of mental imagery exercises. Imagining sports events that are not realized yet, but desired, cause the brain to give electrical reactions as if such events took place (Murru \& Kathleen., 2007; Williams, Cumming \& Balanos., 2010; David, Hardy \& Oliver., 2011). The results of this study show an advantageous effect of the mental imagery training method on the imaging capacity among the judoka compared to other methods of learning such as the observational method and the analytical one. This brings us to perceive the mind / body dialogue where the mental is indeed on the body and the ability to learn in the individual.

[1]. Plessenger, A. (2009).The effects of Mental Imagery on Athletic performance. Research paper at 2007 Washington D.C. The World Bank.

[2]. Hall, C. R., \& Martin, K. A. (1997). Measuring movement imagery abilities: A revision of the Movement Imagery Questionnaire. Journal of Mental Imagery, 21, $143-154$.

[3]. Cumming, J., Nordin, S.M., Horton, R., Reynolds, S. (2006) Examining the direction of imagery and self-talk on dart-throwing performance and self efficacy. The Sport Psychologist, 20, 257-274.

[4]. Eddy, K., Mellalieu, S.D. (2003) Mental Imagery in Athletes with Visual Impairments. Adapted Physical Activity Quarterly, 20(4): 34768.

[5]. Khaled, T. (2004). The effects of mental imagery on the acquisition of motor performance: A literature review with theoretical implications. Journal of mental imagery, 28, 79-114.

[6]. Morris, T., Spittle, M., Watt, A.P. (Eds.).(2005). Technical Aids to Imagery. In Imagery in Sport. (pp. 237-266). Champaign, IL: Human Kinetics.

[7]. Taylor, J \& Wilson, G. (2005). Applying Sport Psychology: Four Perspectives. 117-134. Champaign, IL: Human Kinetics.

[8]. Weinberg, R. \& Gould, D. (2007) Foundations of Sport ad Exercise Psychology, (4th ed., 296-317). Champaign, IL: Human Kinetics.

[9]. Hall, C. (2001). Why athletes and exercisers use imagery. Symposium presented at the annual conference for the Association or the Advancement of Applied Sport Psychology. Oct. 3-7, 2001, Orlando, FL.

[10]. Block, N. (1983). The Photographic Fallacy and the Debate about Mental Imagery. Noûs (17) 651-661.

[11]. Fisher, A.C. (1986). Imagery from a sport psychology perspective. A paper presented at the meeting of the American Alliance for Health, Physical Education, Recreation and Dance, Cincinnati.

[12]. Henschen, K. (2005). Mental Practice: Strategies and Techniques. University of Uttah, Salt Lake City, Utta, U.S.A.

[13]. Smith, D. (1987). Condition that facilitate the development of sport imagery training. The Sport Psychologist, 1, 237-247.

[14]. Mahoney, M., \& Avener, M. (1997). Psychology of the elite athlete: An exploratory study. Cognitive Therapy and Research, 3 , 361-366.

[15]. Orlick, T. (1990). In pursuit of excellence: Leisure Press. A division of Human Kinetics. Champaign, 11. 
[16]. Patterson, K., Nestor, P.J. \& Rogers, T.T. (2007). Where do you know what you know? The representation of semantic knowledge in the human brain. Nature, 8, 976-988.

[17]. Palvio, A. (1985). Cognitive and Motivational functions of imagery in Human performance, Journal of applied sports science, 10, $22-28$.

[18]. Suinn, R. (2005). Behaviour Rehearsal Training for skill Racers Behaviour Therapy 1. $519-520$.

[19]. Jacobson, E.(1931).Electrical measurements of neuromuscular states during mental activities. American Journal of Physiology, $96,115-121$

[20]. Sackett, R. S. (1934). The influences of symbolic rehearsal upon the retention of a maze habit. Journal of General Psychology, 10, 376-395.

[21]. Lang, P. J. (1977). Imagery in therapy: An information-processing analysis of fear. Behavior Therapy, 8, 862-886.

[22]. Lang, P. J. (1979). A bio-informational theory of emotional imagery. Psychophysiology, 16, 495-512.

[23]. Schmidt, R. A. and Wrisberg, C. A. (2004). "Motor Learning and Performance, Third Edition". Champaign, IL: Human Kinetics.

[24]. Williams, S. E., Cumming, J., \& Balanos, M. G. (2010). The use of imagery to manipulate challenge and threat appraisal states in athletes. JSEP, 32: 339-358.

[25]. Smith, A. L., Ntoumanis, N., Duda, J. L., \& Vansteenkiste, M. (2011). Goal striving, coping, and well-being: A prospective investigation of the self-concordance model in sport. JSEP, 33: 124-145.

[26]. Wrisberg, C. A. (2000). Cognitive demand and practice level: Factors in the mental rehearsal of motor skills. Journal of Human Movement Studies, 5, $251-258$.

[27]. Burton, D., \& Raedeke, T. (2008). Sport Psychology for Coaches. 1st. Edition, Human Kinetics, USA.

[28]. Roberts, R., Callow, N., Hardy, L., Markland, D., \& Bringer, J. (2008). Movement imagery ability: Development and assessment of a revised version of the Vividness of Movement Imagery Questionnaire. Journal of Sport \& Exercise Psychology, 30, 200-221.

[29]. Williams, J. (Eds). (2006). Applied Sport Psychology Personal Growth to Peak Performance. 5th. Ed, Mc Graw-Hill, New York.

[30]. Bartholomew, K.J., Ntoumanis, N., \& Thøgersen-Ntoumani, C. (2010). The controlling interpersonal style in a coaching context: Development and initial validation of a psychometric scale. Journal of Sport \& Exercise Psychology, 32, $193-216$.

[31]. Mouratidis, M., Vansteenkiste, M., Lens, W., Sideridis, G. (2008). The motivating role of positive feedback in sport and physical education: Evidence for a motivational model. Journal of Sport and Exercise Psychology, 30, 240-268.

[32]. Sarah, E. W., \& Cumming, J. (2011). Measuring athlete imagery ability: The sport imagery ability questionnaire. JSEP, 33:416-440.

[33]. Smith, A. L., Ntoumanis, N., Duda, J. L., \& Vansteenkiste, M. (2011). Goal striving, coping, and well-being: A prospective investigation of the self-concordance model in sport. JSEP, 33: 124-145.

[34]. Gardner, F., \& Moore, Z. (2006). Clinical Sport Psychology. 2nd. Edition, Human Kinetics, USA.

[35]. Cumming, J., Olphin, T., \& Law, M. (2007). Self-reported psychological states and physiological responses to different types of motivational general imagery. JSEP, 29:629-644.

[36]. Pesce, C., Cereatti, L., Casella, R., Baldari, C., \& Capranica, L. (2007). Preservation of visual attention in older expert orienteers at rest and under physical effort. JSEP, 29:78-99.

[37]. Cox, R. (2007). Sport Psychology Concepts and Applications. 6th. Edition, Mc Graw-Hill, New York.

[38]. Fadiga, L., Craighero,L.(2004). Electrophysiology of action representation. Journal of Clinical Neurophysiology, 21(3), 157-169.

[39]. Jeannrod, M. et Frak, V (1999). Mental Imaging of motor activity in humans. www.I.S.C.fr.Working paper 99-8.

[40]. Gentili, R., Papaxanthis, C., Pozzo, T. (2006) Improvement and generalization of arm motor performance through motor imagery practice. Neuroscience 137:761-772.

[41]. Crosbie, J.H., McDonough, S.M., Gilmore, D.H., Wiggam, M.I. (2004).The adjunctive role of mental practice in the rehabilitation of the upper limb after hemiplegic stroke: a pilot study. Clin. Rehabil. 18 (1), 60-68.

[42]. Voss, M., Ingram, J.N., Haggard, P., Wolpert, D.M. (2006), "Sensorimotor attenuation by central motor command signals in the absence of movement." Nat Neurosci 9(1):26-7.

[43]. Stanley, C.T. (2004). A comparison of coping strategies: Effects upon perceived exertion in a cycling task.

[44]. Skinner, E.A., Edge, K., Altman, J., \& Sherwood, H. (2003). Searching for the structure of coping: A review and critique of category systems for classifying ways of coping. Psychological Bulletin, 129, 216-269.

[45]. Galloway, M. S. (2006), An extension of "One Consultants Experience” focusing on sport Karate. Athletic Insight.

[46]. Lajcik, T.M. (2008). Developing fighting technique through visualization. Journal of Asian martial arts, 17, 78-85.

[47]. Kano, J. (2005). Mind over muscle: Writings from the founder of judo. In Murata,N. (Ed.). Kodansha International.

[48]. Murru, C. E., \& Kathleen, M. G. (2007). Imagining the possibilities: The effects of a possible selves intervention on self-regulatory efficacy and exercise behavior. JSEP, 32:537-554.

[49]. 49) David, T., Hardy, J., Oliver, E. (2011). Effects of self-talk: A systematic review. JSEP, 33:666-687. 